\title{
Economic Effects of a Tax Policy to Reduce Greenhouse-Gas Emissions in Brazil ${ }^{1}$
}

\author{
Os efeitos econômicos da política tributária na redução dos gases de efeito \\ estufa no Brasil
}

Yuri Cesar de Lima e Silva, Luís Sávio Barbosa Dantas² e Nelson Leitão Paes*

\begin{abstract}
Brazil proposes to reduce its greenhouse gas (GHG) emissions by $37 \%$ in relation to the 2005 level in 2025, with an indication to reduce by $43 \%$ in 2030, following the COP-21 agreement in Paris. This study investigates the macroeconomic effects if Brazil adopts a tax on GHG emissions as a way to meet its commitments and similar to the double dividend thesis. A neoclassical model of growth with the introduction of the environment and fiscal policy was used. It was calculated that a tax of US\$ 100/tCO2 would be sufficient for the country to achieve the reduction targets. The double dividend hypothesis was observed in the Brazilian case and the best results occurred when the capital taxation was reduced.
\end{abstract}

Keywords: Taxes; Emissions; Double Dividend; Growth Model; Environment Policy

Resumo: O Brasil propõe reduzir suas emissões de gases de efeito estufa (GHG) em 37\% em relação ao nível de 2005 em 2025, com indicação de reduzir em 43\% em 2030, seguindo o acordo COP-21 em Paris. Este estudo investiga os efeitos macroeconômicos caso o Brasil adote um imposto sobre as emissões de GHG como forma de cumprir os compromissos assumidos e similar a tese do duplo dividendo. Um modelo neoclássico de crescimento com a introdução do meio-ambiente e da política fiscal foi utilizado. Calculou-se que um imposto de US\$100/tCO2 seria suficiente para o país atingir as metas de redução. A hipótese do duplo dividendo foi observada no caso brasileiro e os melhores resultados ocorreram quando a tributação do capital foi reduzida.

Palavras-chaves: Impostos; Emissões; Duplo Dividendo; Modelo de Crescimento; Política Ambiental

JEL Code: H22; H23; H27

\footnotetext{
${ }^{1}$ Submissão: 30/07/2019; aprovação: 15/11/2019. DOI: 10.5380/re.v41i75.68240.

${ }^{2}$ The opinions expressed in this paper are exclusively those of the author(s) and do not necessarily reflect the views of the Central Bank of Brazil or its members.

* Respectively, Department of Economics, Federal University of Roraima (UFRR). E-mail: yuricesar_silva@hotmail.com. ORCID: 0000-0002-2110-6256. Central Bank of Brazil. E-mail: savio.dantas@bcb.gov.br. Department of Economics, Federal University of Pernambuco (UFPE). E-mail: nlpaes@yahoo.com.br. ORCID: 0000-0001-6246-4503.
}

(i) (\$) Esta publicação está licenciada sob os termos de

Creative Commons Atribuição-Não Comercial 4.0 Internacional. 


\section{Introduction}

The effects of global warming and consequent climate change due to anthropogenic greenhouse gases (GHGs) emissions have long been debated at various climate conferences held by the United Nations (UN) which have been attended by the world's largest economies. The Kyoto Protocol, signed in 1997, was the first instrument that legally bound developed countries to explicit GHG reduction targets. Since then, many other meetings have taken place to monitor and adjust these objectives. The last stage of the global effort to combat climate change was defined at the 21st Conference of the Parties (COP-21), with the signing of the Paris agreement, which took place in the French capital in December 2015 and, to date, has 165 countries that have presented national targets for reducing GHG into the atmosphere.

Brazil is a signatory to the Paris agreement and, in its nationally determined intended contribution (INDC) submitted to COP-21, committed to reduce GHG emissions by $37 \%$ below 2005 levels in 2025 and, as an indication, to further reduce them by $43 \%$ below 2005 levels in 2030 .

The environmental policies proposed in the INDC to meet the target submitted to COP-21 are: increase the participation of biofuels and other renewable energies in the national energy mix; strengthen policies in the forestry sector and land use change; strengthen low carbon agriculture policy; promote new standards for clean technologies and expand energy efficiency and low carbon infrastructure in industry; and promote improvements in transport and public transport infrastructure in urban areas.

Mainly due to the vast expanse of native forest in its territory, a large part of Brazil's GHG emissions are associated with changes in land use and forest (55\% of total emissions) according to SEEG (2016). Thus, the data in Figure 1 shows that there was a reduction of around $43.8 \%$ of the total emissions between 2005 and 2015 and that these are strongly correlated with the deforestation reduction. However, when we consider the data without the occurrence of changes in land and forest use, which correspond to almost $45 \%$ of total emissions in Brazil, there is an increase in emissions of more than $33 \%$ in the same period, and this time it is quite correlated with the Gross Domestic Product of the country (see figure 2).

The introduction of a Pigouviano tax could create a mechanism capable of reducing the incentives to produce goods that are having a negative impact on 
society that outweighs the benefits generated by them. As previously seen, GHG emissions are being treated as one of the main problems for global warming and for survival of the future generations on Earth. Introducing some type of emission tax could discourage polluting production technologies and, at the same time, create incentives for the evolution of clean technologies.

\section{Figure 1 - Carbon emissions ( $\left.\mathrm{CO}_{2} \mathrm{e}(\mathrm{t}) \mathrm{GTP}-\mathrm{AR5}\right)$ by category and annual deforestation (in hectares) in Brazil between 1990 and 2015}

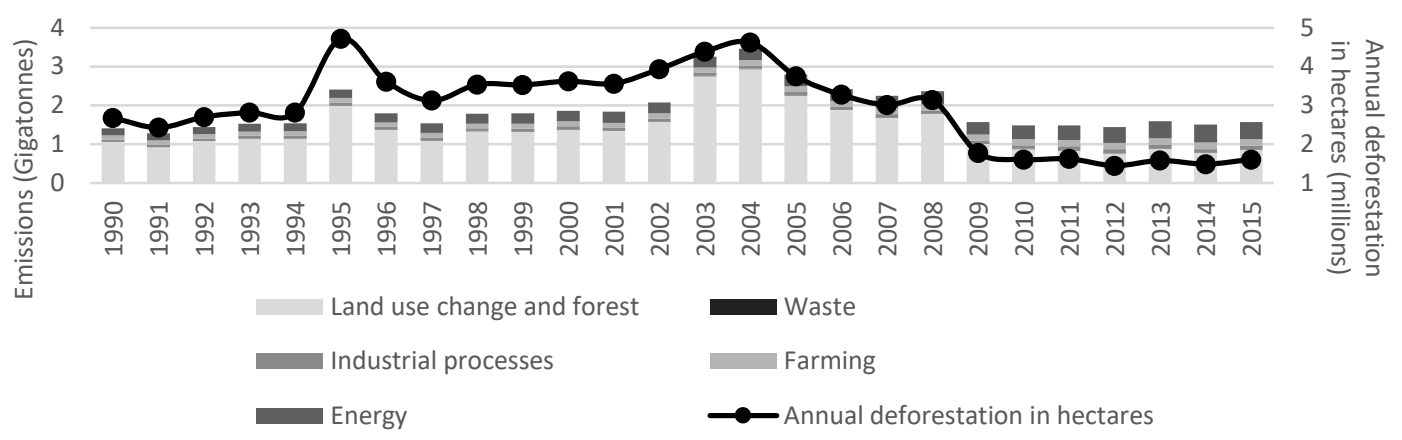

Data Source: System Study Greenhouse Gas Emissions Estimates - SEEG (2016) ${ }^{3}$.

In other countries, taxation or carbon markets are already part of the environmental policies to reduce GHG emissions and these policies have proven to be more efficient when emissions are more directly linked to production activities (Partnership for Market Readiness, 2017).

\footnotetext{
${ }^{3}$ The data used in Figures 1 and 2 are available in: <http://plataforma.seeg.eco.br/>.
} 
Figure 2 - Carbon emissions ( $\mathrm{CO}_{2}$ e(t) GTP-AR5) by category, excluding land and forest use, and Brazil's Gross Domestic Product (in billions of 2014 Reais) between 1990 and 2015

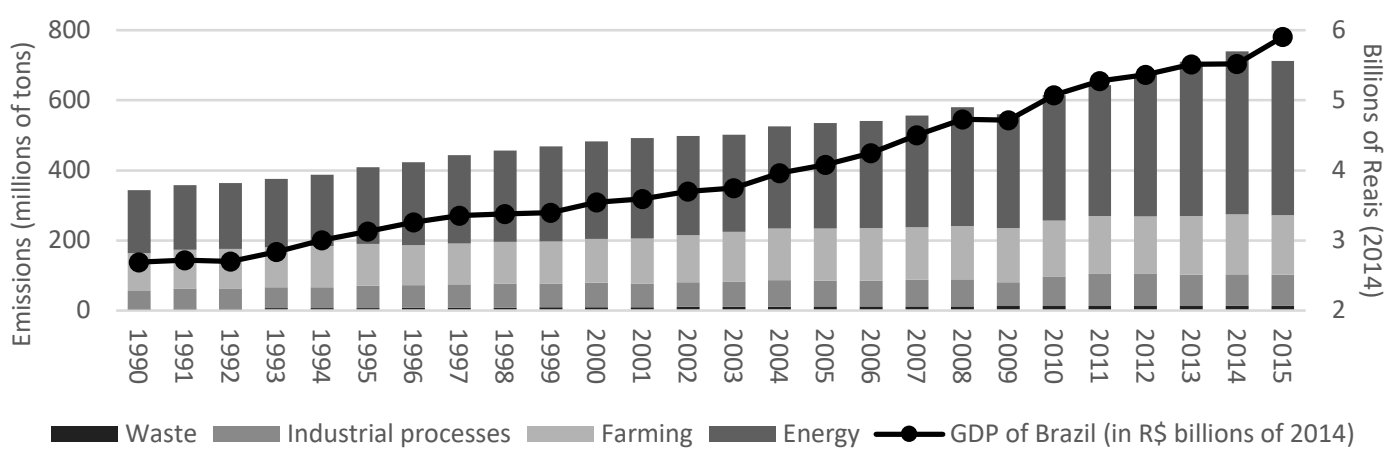

Data Source: System Study Greenhouse Gas Emissions Estimates - SEEG (2016).

Brazil does not yet have a market-based instrument to control GHG emissions. In this study, we investigated the macroeconomic effects in Brazil in case the country adopted a GHG emission tax to fulfill the carbon reduction commitment assumed in international agreements. As a second objective, we tried to simulate the "double dividend" thesis, that is, if the reduction of emissions due to the new tax is accompanied by a reduction of inefficiencies, since the increase in revenue would be offset by the reduction of another tax.

Therefore, we used a neoclassical growth model with the introduction of environment and fiscal policy. The environmental sector of the model was inspired by the works of Heutel (2012), and Angelopoulos et al. (2010), and the tax structure of the model is inspired by the article by Araújo and Ferreira (1999).

The analysis of the effects of formal policies to control GHG emissions on the economy has been carried out through two different categories of economicenvironmental models. The first comprises the Computational General Equilibrium (CGE) models, very present in the literature and based on a structure of inputs and outputs. Examples of works using this methodology are: Viguier et al. (2003), who studied the impacts of the Kyoto Protocol on the European economy; Babiker et al. (2000), who studied the impacts of the Kyoto Protocol on developing countries; and Feijó and Júnior (2009) that investigated the impacts of the Kyoto Protocol in Brazil.

The second category appeared in the most recent environmental approach and has a more macroeconomic perspective, comprising general equilibrium 
models with a micro-foundation approach that have dynamic equations capable of describing the economic and environmental relations studied (Fischer and Heutel, 2013). Some of the studies that used models with these characteristics are: Angelopoulos et al. (2010), who compared the performance of three different environmental policies: taxes, emissions limits and a set of policies such as those adopted in the Kyoto Protocol; Heutel (2012), who analyzed the fiscal policies and the emissions cap, seeking to find the optimal dynamic behavior of these policies, subject to productivity shocks; and Leal et al. (2015), who calibrated the Heutel (2012) model for the Brazilian case and concluded that the optimal balance is a positive and dynamic tax rate, increasing in periods of economic expansion, and decreasing in periods of crisis.

This article is linked to the second category of models that were previously exposed and intends to contribute to this literature by creating a model capable of simulating what would be the effects on Brazilian macroeconomic variables if a GHG emissions tax policy has been adopted to meet the country's commitments in international agreements to reduce these gases. In addition, the article is the first to investigate the thesis of the "double dividend" in Brazil, in the case of introducing of the emissions tax, and to create a more interesting analytical capacity to understand the tax effect of the introduction of the policy in the model.

The results of simulations demonstrate that, with the introduction of the emissions tax, the exact magnitude of the Paris agreement in Brazil would require a reduction in production, consumption, capital stock and working hours. However, these negative results would be compensated in the short term by an improvement in the quality of the environment which could increase the level of welfare of the agents. In the long term, the welfare would return to a level close to the initial steady state. Short-terms results also confirm the double dividend hypothesis and explain that the best economic results would be obtained by reducing the income tax rate on capital.

The article is structured in the following sections. In section 2, we describe the model used and introduce the definition of equilibrium. In section 3 we present the calibration of the model. The results are presented in section 4 , where the simulations and the sensitivity analysis of the model are performed. Finally, in section 5 , we have final considerations. 


\section{Model}

The model has the structure of a neoclassical economic growth model with an introduction of environment and environmental policy. Assuming there is a continuum of identical private agents of infinite life in the economy, the usefulness of the function of these agents is composed by consumption, quality of the environment and leisure. Private agents consume, save, and own the firms that produce a single good under a perfect competition regime. When producing the good, the companies emit GHGs and this damages the environmental quality. Private agents consider environmental quality as a public good, i.e., they do not internalize the effects of their actions on the environment. Therefore, there is a need for government intervention.

The agents have perfect information symmetry and seek to optimize their choices in response to government's environmental policy. Therefore, to reduce taxes, companies adjust abatement costs capable of changing the emission/product ratio.

\subsection{Households}

There is a continuum $(0 \leq j \leq 1)$ of households that maximize their utility expectations subject to a standard budget constraint. The preference of household $j$ is given by:

$$
U\left(C_{t}, Q_{t}, h_{t}\right)=E_{t}\left[\sum_{t=0}^{\infty} \beta^{t}\left\{\frac{\left[\left(C_{t}\right)^{\eta}\left(Q_{t}\right)^{\omega}\left(1-h_{t}\right)^{1-\eta-\omega}\right]^{1-\sigma}}{1-\sigma}\right\}\right]
$$

Where $\beta$ denotes the intertemporal discount factor, $C_{t}$ and $h_{t}$ respectively, are the level of consumption and the working hours offered by the $j$ th household in a period $t$. Variable $Q_{t}$ corresponds to environmental quality at the beginning of period $t$. Individuals appreciate environmental quality. People prefer to live in good quality environments and avoid bad ones. They are not indifferent to the quality of the environment. One of the reasons households' value environmental quality is related to health ${ }^{4}$. The parameters $\eta, \omega$ and $(1-\eta-\omega)$ respectively,

\footnotetext{
${ }^{4}$ Pollution is the largest environmental cause of disease and premature death in the world today. Polluted air was responsible in 2015 for 6.4 million deaths worldwide. Air pollution was responsible in 2015 for $21 \%$ of all cardiovascular deaths worldwide, $25 \%$ of ischemic heart disease deaths, $24 \%$ of stroke deaths, and $27 \%$ of lung cancer deaths. Additionally, ambient air pollution appears to be an important although not yet quantified risk factor for neurodevelopmental disorders in children and neurodegenerative diseases in adults. (Landrigan, 2017).
} 
are the weights given to consumption, to environmental quality and to leisure; While $\sigma \geq 1$ is the measure of risk aversion or the inverse of the intertemporal elasticity of substitution between consumption, environmental quality and leisure.

The budget constraint faced by the agents in each period is described below:

$$
\left(1+\tau_{c}\right) C_{t}+I_{t}=\left(1-\tau_{h}\right) w_{t} h_{t}+\left(1-\tau_{K}\right) r_{t} K_{t}+T_{t}
$$

Where, $I_{t}$ is the level of investment, $w_{t}$ and $r_{t}$ are income from work (wage) and rent from capital stock (interest rate), respectively, and $T_{t}$ is the lump sum transfer from the government to the households. The government tax structure is composed of four different tax rates; $\tau_{c}, \tau_{h}, \tau_{K}$ and $\tau_{e}$, which focus on consumption, labor income, capital income and emissions, respectively. Thus, the left side of equation (2) indicates where households allocate their resources, whether in consumption or investment, and the right side demonstrates the availability of income in period $t$.

Capital evolves in the standard form of neoclassical growth models, according to equation (3):

$$
K_{t+1}=(1-\delta) K_{t}+I_{t}
$$

In which the parameter $\delta$ denotes the rate of capital depreciation. Therefore, the problem of households is to maximize utility (1) subject to the budget constraint (2) and the working capital law (3). The equilibrium equations resulting from the first order conditions of this maximization problem are:

$$
\begin{gathered}
\frac{\left(1-h_{t}\right)}{C_{t}}=\frac{(1-\eta-\omega)\left(1+\tau_{c}\right)}{\eta\left(1-\tau_{h}\right) w_{t}} \\
1=\beta E_{t}\left\{\left(\frac{C_{t+1}^{\eta} Q_{t+1}^{\omega}\left(1-h_{t+1}\right)^{1-\eta-\omega}}{C_{t}^{\eta} Q_{t}^{\omega}\left(1-h_{t}\right)^{1-\eta-\omega}}\right)^{1-\sigma}\left(\frac{C_{t}}{C_{t+1}}\right)[(1-\delta)\right. \\
\left.\left.+\left(1-\tau_{k}\right) r_{t+1}\right]\right\} \\
\left(1+\tau_{c}\right) C_{t}+\left[K_{t+1}-(1-\delta) K_{t}\right] \\
=\left(1-\tau_{h}\right) w_{t} h_{t}+\left(1-\tau_{k}\right) r_{t} K_{t}+T_{t}
\end{gathered}
$$




\subsection{Environmental structure}

The utility of households is affected by the quality of the environment available at the beginning of each period; however, this variable is not part of the set of choices of these agents. In our model, the environmental quality was inspired by the work of Angelopoulos et al. (2010) and evolves over time according to:

$$
Q_{t+1}=(1-\phi) \bar{Q}+\phi Q_{t}-f e_{t}
$$

Where, $\bar{Q} \geq 0$ corresponds to the quality of the environment without pollution, the parameter $\phi \in(0,1)$ measures the degree of environmental persistence and the parameter $f \in(0,1)$ corresponds to a measure of adjustment for the impact of emissions on environmental quality.

Emissions $\left(e_{t}\right)$, in turn, is similar to the formulation present in Heutel's work (2012), and is a function of the emission reduction fraction $\left(\mu_{t}\right)$ and the total production $\left(Y_{t}\right)$, which are variables defined by the firms. Therefore, emissions are formally defined as:

$$
e_{t}=b\left(1-\mu_{t}\right) Y_{t}^{(1-\gamma)}
$$

Whose parameter $(1-\gamma)$ is the elasticity of the emissions in relation to output and parameter $b$ defines the relationship between emissions and the output of the economy.

\subsection{Firms}

Firms seek to maximize their profits, constrained by available technology. The profit function of the representative company is given by:

$$
\pi_{t}=Y_{t}-\tau_{e} e_{t}-r_{t} K_{t}-w_{t} h_{t}-Z_{t}
$$

In which revenue comes exclusively from production and the costs are derived from the payment of emission taxes, capital rent, payment of wages and abatement costs $\left(Z_{t}\right)$. The production function is defined as a Cobb-Douglas function, as follows:

$$
Y_{t}=A_{t} K_{t}^{\alpha} h_{t}^{1-\alpha}
$$

In which, $A_{t}$ is the total productivity factor and $\alpha$ measures the participation in the capital stock. The abatement technology cost follows the work of Nordhaus 
(2008), widely used in the literature [Heutel (2012); Leal et al. (2015); Annicchiarico and Dio (2017)], and is formally defined as:

$$
Z_{t}=Y_{t} \theta_{1} \mu_{t}^{\theta_{2}}
$$

Where, $\theta_{1}$ measures the menu of existing technological alternatives and $\theta_{2}$ shows the degree of non-linearity in the costs for deeper emissions cuts. These parameters were defined in the Nordhaus (2008) RICE model ${ }^{5}$, where the former varies according to the country, assuming that the countries are at different stages of the technological process, while the second is fixed in time and space and has a value of 2.8, making the function assume an almost cubic configuration. In this sense, the abatement cost function defines the cost the company will incur to define how much it will reduce emissions in each period, therefore the cost will always be a fraction of the production in each period.

The equilibrium equations resulting from the first order conditions of the firm's profit maximization problem are:

$$
\begin{gathered}
w_{t}=\frac{\left(1-\theta_{1} \mu^{\theta_{2}}\right)(1-\alpha) Y_{t}-\tau_{e} b(1-\mu)(1-\alpha)(1-\gamma) Y_{t}^{1-\gamma}}{h_{t}} \\
r_{t}=\frac{\left(1-\theta_{1} \mu^{\theta_{2}}\right) \alpha Y_{t}-\tau_{e} b(1-\mu) \alpha(1-\gamma) Y_{t}^{1-\gamma}}{K_{t}} \\
\tau_{e} b Y_{t}^{-\gamma}=\theta_{1} \theta_{2} \mu^{\theta_{2}-1}
\end{gathered}
$$

\subsection{Government}

The model assumes that the government uses part of its revenues with exogenous expenditures and the remainder is transferred back to the households. The implicit budget constraint for the government is defined as:

$$
G_{t}+T_{t}=\tau_{c} C_{t}+\tau_{h} w_{t} h_{t}+\tau_{K} r_{t} K_{t}+\tau_{e} e_{t}
$$

Therefore, government expenditures $\left(G_{t}\right)$ and transfers to families $\left(T_{t}\right)$ are financed by taxes paid by households and firms, as defined above.

\footnotetext{
${ }^{5}$ The regional integrated model of climate and the economy (RICE model) is a model built by Nordhaus (2008) to examine alternative results for emissions, climate change and damage under different policy scenarios. The data used in the parameterization of the abatement cost function came from the results generated by this model. For more information see: < http://www.econ.yale.edu/ nordhaus/homepage/RICEmodels.htm>.
} 


\subsection{Competitive equilibrium}

Households solve a dynamic problem by taking prices and tax rates as data. These agents choose sequences of consumption, capital and labor supply in order to maximize the utility function (1), restricted to the budget constraint (2), the hypothesis on the law of capital evolution (3) and assuming that the initial capital is different from zero $\left(K_{0} \neq 0\right)$.

Firms, in turn, are faced with a static problem. They take on prices $r_{t}$ and $w_{t}$. The values of each of the inputs are: interest rate and wages, respectively, as indicated, and choose each quantity of inputs $\left(K_{t}\right.$ and $\left.h_{t}\right)$, the amount of emissions to be reduced $\left(\mu_{t}\right)$ and the product $\left(Y_{t}\right)$ which maximize their profit function (9), restricted to the production function (10) and abatement costs (11). It should also be noted that the only tax rate of the government that interferes in the behavior of the firms is the rate of tax on emissions $\left(\tau_{e}\right)$.

The competitive balance of the model is formed by a sequence of prices $\left\{w_{t}, r_{t}\right\}_{t=0}^{\infty}$ and a sequence of quantities $\left\{Y_{t}^{*}, C_{t}^{*}, K_{t}^{*}, h_{t}^{*}, T_{t}^{*}, Q_{t}^{*}, e_{t}^{*}, \mu_{t}^{*}, Z_{t}^{*},\right\}_{t=0}^{\infty}$, in such a way that:

a) Given prices, the allocation $\left\{C_{t}^{*}, K_{t}^{*}, h_{t}^{*}\right\}_{t=0}^{\infty}$ solves the problem of households - equations (1) to (3).

b) Given prices, the allocation $\left\{K_{t}^{*}, h_{t}^{*}, \mu_{t}^{*}\right\}_{t=0}^{\infty}$ solves the problem of firms - equations (9) to (11).

c) For each period of time, the goods, labor and capital markets are in balance. As labor and capital markets are already implicitly in equilibrium, it is only necessary to balance the goods market:

$$
C_{t}+I_{t}+G_{t}=A_{t} K_{t}^{\alpha} h_{t}^{1-\alpha}
$$

\section{Model Calibration}

The model was calibrated using the $2014 \mathrm{data}^{6}$ and we obtained the model parameters as follows. First, we obtain the gross operating surplus and gross mixed income type income data from the National Accounts and the average interest rate on new non-marked credit operations - Non-financial corporations of the Central

\footnotetext{
${ }^{6}$ The results for calibrations using the data for 2010 and 2012 are shown in Figure A.1 of the Appendix.
} 
Bank of Brazil ${ }^{7}$. The capital-output ratio of the economy can be obtained through equation (13), remembering that Brazil still does not have an emissions tax, therefore the values of the emission reduction fraction $\left(\mu_{S S}\right)$ and the abatement technology cost $\left(Z_{S S}\right)$ are equal to zero in the steady state, as companies have no incentive to reduce their emissions before the tax is created.

$$
\frac{K_{S S}}{Y_{S S}}=\frac{\alpha}{r_{S S}}
$$

In view of this information, considering that in the steady state, the investment only restores the depreciated capital of the economy and with the proportion of the investment in GDP that comes from the National Accounts, we obtain the value of the depreciated capital ratio $(\delta)$.

The fiscal parameters were obtained the RFB (2016), where the aggregation of taxes was carried out as follows:

Labor income tax $=$ Personal income tax + payroll tax $=10.79 \%$ of GDP.

Capital gains tax $=$ Corporate income tax + Non-allocable withholdings + Provisional contribution on financial transaction $(\mathrm{CPMF})+$ Tax on financial transactions $(\mathrm{IOF})+$ Property tax $=5.09 \%$ of GDP.

Consumption tax $=$ Tax on Goods and services + Other taxes $=16.02 \%$ of GDP. Using data from the relations between consumption, capital income and labor income on GDP, we find the tax rates on them, using equations (18), (19) and (20).

$$
\begin{gathered}
\tau_{C}=0,1602 /(C / Y) \\
\tau_{K}=0,0509 /(r K / Y) \\
\tau_{h}=0,1079 /(1-\alpha)
\end{gathered}
$$

We calculate the discount factor $(\beta)$ by equation $(21)$.

$$
r_{S S}=\left(\frac{1}{1-\tau_{k}}\right)\left[\frac{1}{\beta}-(1-\delta)\right]
$$

To obtain the utility parameters of equation (1), since there is no well defined value for $\omega$ in the literature, we use the value of 0.125 for the base model, and we will do sensitivity tests on this parameter. The value found in Angelopoulos et al. (2010) for this parameter is 0.4 .

\footnotetext{
7 The data used can be found at: <https://www3.bcb.gov.br/sgspub/localizarseries/localizarSeries.do?method=prepararTelaLocalizarSeries $>$.
} 
Regarding the parameter $\eta$, our objective was to calibrate it so that the value of hours worked $(h)$ was close to 0.2619 , which is equivalent to 44 hours of work per week, the maximum allowed by Brazilian legislation. We use the equilibrium equation (4) between consumption and leisure to obtain the relation $\eta /(1-\omega-$ $\eta)$. Thus, whenever the value of $\omega$ is defined, we calibrate the value of $\eta$ to be approximately $68 \%$ of $(1-\omega-\eta)$, making the value of $(h)$ as close to 0.2619 as possible, but without exceeding it. Finally, we consider the value of the risk aversion parameter $(\sigma)$ to be equal to 2 , which is the same value found in Leal $e t$ al. (2015), standard in the Brazilian literature.

Some of the environmental parameters were obtained in the literature. In the function that determines the quality of the environment, the environmental persistence $(\phi)$ and the quality of the environment without pollution $(\bar{Q})$ were captured from the work of Angelopoulos et al. (2010). The parameters of the cost function of the abatement technology, the coefficient $\left(\theta_{1}\right)$, and the exponent $\left(\theta_{2}\right)$, emerged from the work of Nordhaus (2008).

Regarding the parameters of the emission function, the values of $b$ and $\gamma$ are 0.1946 and 0 , defined by the best fit between the annual series of the $\mathrm{CO}_{2}$ emission variables, from the burning of fossil fuels, measured by the Global Carbon Budget and the GDP of Brazil between 1960 and 2014. Table 1 summarizes the values used for parameters in our model. 
Table 1 - Parameterization for the Brazilian economy in 2014

\begin{tabular}{clc}
\hline Parameters & \multicolumn{1}{c}{ Description } & Value \\
\hline$A$ & Technological productivity parameter (Hicks-neutral) & 1.0000 \\
$\alpha$ & Capital share in profit & 0.4884 \\
$\beta$ & Inter-temporal discount rate & 0.9260 \\
$\delta$ & Capital depreciation & 0.0674 \\
$\tau_{c}$ & Consumption tax rate & 0.2612 \\
$\tau_{K}$ & Capital gains tax & 0.1043 \\
$\tau_{h}$ & Labor Income Tax & 0.2110 \\
$\tau_{e}$ & Emission tax & 0.0000 \\
$\omega$ & Weight of environmental quality in utility function & 0.1250 \\
$\eta$ & Consumption weight as a function of utility & 0.3500 \\
$\sigma$ & Risk aversion coefficient & 2.0000 \\
$1-\gamma$ & Elasticity of emissions in relation to production & 1.0000 \\
$b$ & Emissions in relation to GDP (Kg/U\$) & 0.1946 \\
$\theta_{1}$ & Cost-Benefit Function Coefficient & 0.0418 \\
$\theta_{2}$ & Exponent of the abatement cost function & 2.8000 \\
$\phi$ & Persistence of environmental quality & 0.9000 \\
$\bar{Q}$ & Environmental quality without pollution & 1.0000 \\
$f$ & Impact of emissions on the environmental quality & 0.1000 \\
\hline
\end{tabular}

Production $\left(Y_{S S}\right)$, capital stock $\left(K_{S S}\right)$ and hours worked $\left(h_{S S}\right)$ were calculated from equations (4), (10) and (12) in the steady state, considering that is no emission tax at the initial steady state, so $\tau_{e}$ and $\mu$ are zero.

With the value of these variables, it was possible to calculate the values of wage $\left(w_{S S}\right)$, consumption $\left(C_{S S}\right)$, transfers $\left(T_{S S}\right)$, emissions $\left(e_{S S}\right)$ and environmental quality $\left(Q_{S S}\right)$. Therefore, Table 2 shows the steady state values before the creation of the emissions tax.

Table 2 - Steady state values

\begin{tabular}{cll|cll}
\hline Variable & Description & Value & Variable & Description & Value \\
\hline$Y_{S S}$ & Product & 0.7300 & $e_{S S}$ & Emissions & 0.1421 \\
$K_{S S}$ & Capital & 2.1692 & $Q_{S S}$ & Enviromental quality & 0.8579 \\
$h_{S S}$ & Labor hours & 0.2581 & $\mu_{S S}$ & Mitigation & 0.0000 \\
$C_{S S}$ & Consumption & 0.4477 & $Z_{S S}$ & Abatiment cost & 0.0000 \\
$r_{S S}$ & Interest rate & 0.1644 & $G_{S S}$ & Government spending & 0.1362 \\
$w_{S S}$ & Wages & 1.4469 & $T_{S S}$ & Transfers & 0.0967 \\
\hline
\end{tabular}




\section{Results}

After calibration and solution of the model, simulations were performed considering different values for the tax rate that affects emissions. In all exercises, the period of the time used in the experiments is one year and one hundred periods were simulated. The values assumed by the variables are measured as the percentage variation of the initial steady state value, where the value of the tax rate is zero.

In the first experiment, five different values were simulated for the emission tax rate, the values used were: $1 \%, 2.5 \%, 5 \%, 7.5 \%$ and $10 \%$. In all cases, in the initial period, the tax rate assumes a value equal to $0.1 \%$ and only assumes the value established by the policy after 30 periods, having a linear growth during that time. After the thirtieth period, the value remains fixed until the final period. This methodology was used to reconcile the exercise (in a very simplified way) with what occurs in international treaties, where a period of time is established for the country to achieve the proposed target.

Therefore, the trajectories presented in the graphics of Figure 3 reflect changes in the economy after the introduction of the emissions tax. Thus, as the relation between prices in the economy is modified, we notice that real wages fall in all scenarios. The fall in wages reduces the incentive to work, reducing the hours worked, which consequently increase leisure hours. In the short term, interest rates (return on capital gains) also decrease, inducing investment cuts and reducing capital stock. With the fall in hours worked and capital stock, the product decreases and consequently consumption.

On the environmental side, the introduction of the emissions tax causes entrepreneurs to allocate resources in the reduction of technologies to reduce the emission/product ratio. Only with $\tau_{e}=10 \%$, entrepreneurs decide to reduce a fraction of emissions by around $38 \%$ in the thirtieth period, which is consistent with Brazil's targets in international agreements. This way, the environmental quality improves. This increase in environmental quality combined with an increase in leisure time means that the welfare of agents improves in the short term, even if there is a reduction in consumption. However, in the long run we realize that welfare returns to a value somewhat below that found in the initial steady state. Note, however, that when we assume lower values for the emissions tax rate, 
welfare remains positive in the long term, but the value of the emission reduction target assumed by Brazil cannot be reached.

\section{Figure 3 - Transition path from the simulation of different values to the emission tax}
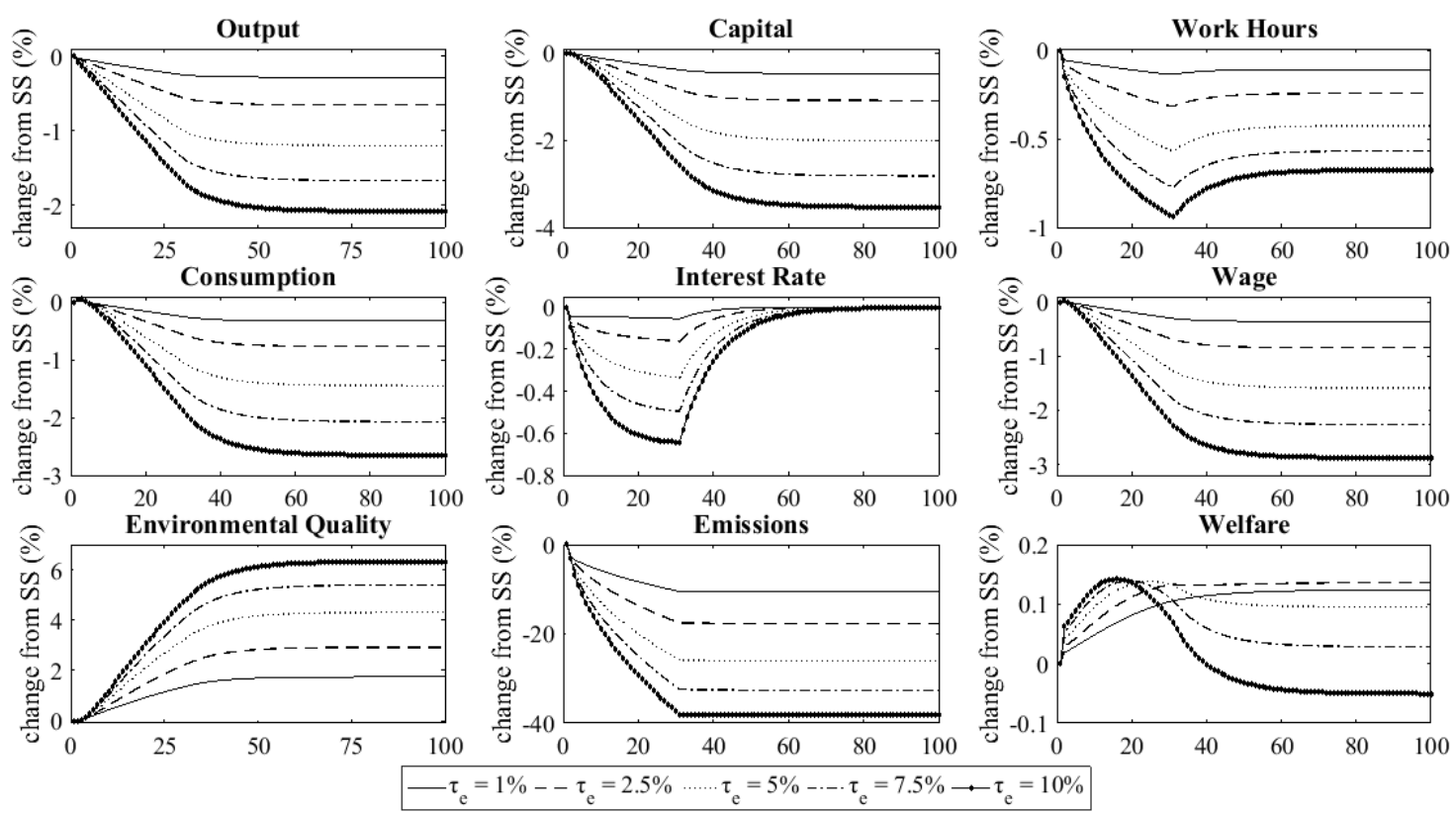

Note: Values reported in the caption for $\tau_{e}$ are only assumed after the 30th period. Between the first period, which assumes a value equal to $0.1 \%$, and at period 30 , the rate increases linearly.

As a complementary exercise, we calculated the values in US\$ per $\mathrm{tCO}_{2}$ for each of the previously simulated rates. However, since our objective is to understand the macroeconomic effects of introducing an environmental policy in Brazil, we recognize that the environmental structure of the model is rather simplified but serves the purpose of our work. Therefore, the absolute values found here should be considered with caution.

Since, in the model, our tax rates are percentage values of emissions and the prices of emissions are based on the value of the economy's products, we were able to price the tax using the value of Brazil's GDP in 2014 for each of the rates used. The tax values in US\$ per ton of $\mathrm{CO}_{2}$ emitted and the impact of these taxes on emissions reduction can be seen in Table 3 below:

However, even with all the warnings pointed out previously, the values found are not so divergent from those in the literature for Brazilian data. It is important to note that the models used in these studies consider the interactions 
among the different sectors of the economy, being closer to an input-output-based approach (CGE models) than the macroeconomic approach used in our model.

Table 3 - Emission tax and reduction impact

\begin{tabular}{lccccc}
\hline & $\boldsymbol{\tau}_{\boldsymbol{e}}=\mathbf{1} \%$ & $\boldsymbol{\tau}_{\boldsymbol{e}}=\mathbf{2 . 5} \%$ & $\boldsymbol{\tau}_{\boldsymbol{e}}=\mathbf{5} \%$ & $\boldsymbol{\tau}_{\boldsymbol{e}}=\mathbf{7 . 5} \%$ & $\boldsymbol{\tau}_{\boldsymbol{e}}=\mathbf{1 0} \%$ \\
\hline Value (US\$ per tCO 2 ) & 10.00 & 25.00 & 50.00 & 75.00 & 100.00 \\
Emissions reduction $(\%)$ & 10.52 & 17.63 & 26.01 & 32.60 & 38.22 \\
\hline
\end{tabular}

In the simulation of the Ferreira Filho and Rocha (2008) model, a rate of US\$ 10 per $\mathrm{tCO}_{2}$ was able to reduce $6.83 \%$ of emissions. On the other hand, the model used in Gurgel and Paltsev (2014) pointed out that in a scenario where there is an increase in rates from U\$ 28 per $\mathrm{tCO}_{2}$ in 2015 to U.S. \$ 290 in 2030, companies were induced to a $21 \%$ reduction in GHG emissions in $2015,39 \%$ in 2020, 50\% in 2025 and 58\% in 2030. While Lucena et al. (2016) simulated an increase from US\$ 50 per $\mathrm{tCO}_{2}$ in 2020 to $\$ 162$ per $\mathrm{tCO}_{2}$ in 2050 that was able to induce a $60 \%$ reduction in emissions when compared to the simulated model without an environmental policy.

Finally, the World Bank states that "Most scenario analyses indicate an average global carbon price of between $\mathrm{US} \$ 80 / \mathrm{tCO}_{2}$ and $\mathrm{US} \$ 120 / \mathrm{tCO}_{2}$ and in 2030 would be consistent with the goal of limiting the global warming to $2{ }^{\circ} \mathrm{C}$ " (Kossoy and Peszko, 2015, p. 24), although some studies highlight that COP-21 will not be enough to reach the $2^{\circ} \mathrm{C}$ reduction.

Sensitivity tests were performed for four important parameters of our model - the parameter that measures the importance attributed by households to environmental quality $(\omega)$, the parameter that measuring the impact of emissions on the environmental quality $(f)$, the parameter that measuring the relationship between the emissions and output of the economy $(b)$ and the parameter that measures the menu of existing technological alternatives $\left(\theta_{1}\right)^{8}$ as shown in Figure 4.

\footnotetext{
${ }^{8}$ The values used for the sensitivity of $\theta_{1}$ were taken from the RICE model. The years used in each case are: 2005 (0.0529); 2015 (0.0418); 2025 (0.0348); 2045 (0.0250); e 2065 (0.0186).
} 
The numbers do not suggest a high sensitivity of welfare in relation to the range of values of each of the analyzed parameters. In general, in all the simulations carried out, the introduction of emissions taxes has little impact on welfare.

\section{Figure 4-Welfare transition trajectory in the simulation of different values for parameters}
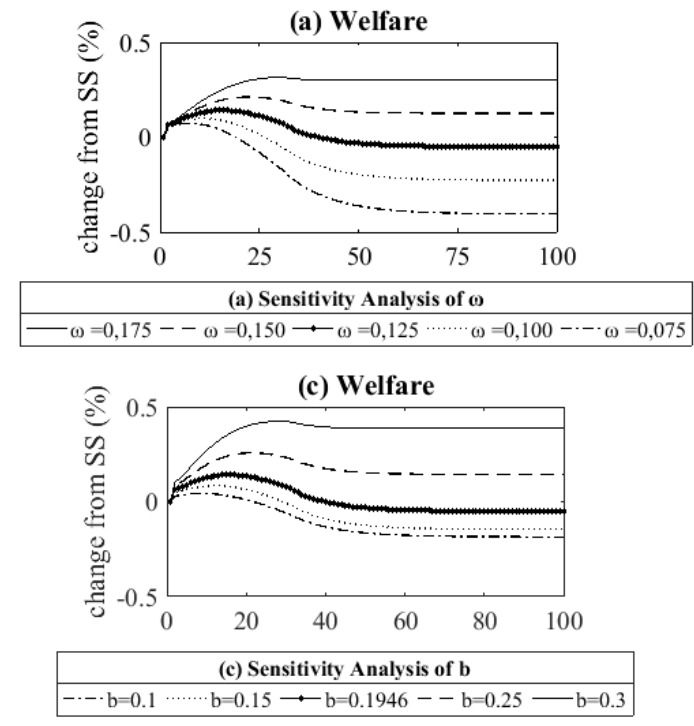
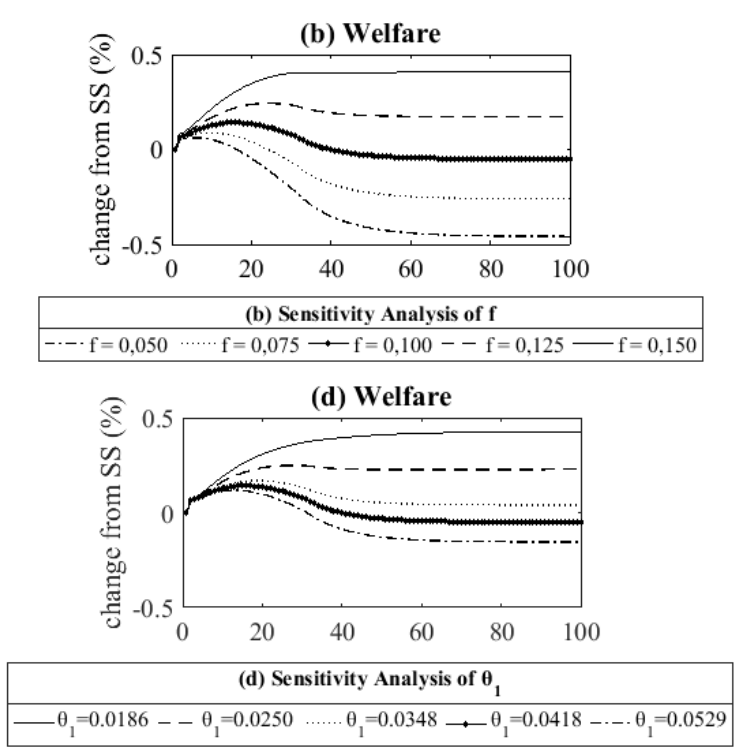

Next, we will present the results of the model with the introduction of the double dividend thesis, That is, we try to analyses whether the institution of the emissions tax and the reduction of the value of another existing tax would result in a double gain in welfare; a reduction in emissions and a reduction in tax distortions. For this exercise, we used the value of $10 \%$ for the emissions tax rate (US\$100.00 per ton of $\mathrm{CO}_{2}$ ) that is the value capable of generating a reduction in emissions at a level close to what Brazil has committed to, based on the Paris Agreement.

Table 4 shows the expected long-term results with the introduction of the double dividend thesis on the macroeconomic and environmental variables of the model, as well as to demonstrate the composition of tax collection in relation to GDP, for each of the possible reductions in the rates.

When we look at the long-term results, we cannot say that the double dividend thesis has generated a double welfare gain. In fact, we observed a small welfare reduction $(-0.05 \%)$ in relation to the "first dividend", which would be the improvement in environmental quality, a fact that can be observed in the column 
"Without DD" of Table 3. This can be explained by the tax rate used to carry out the exercise. The biggest problem with Brazil's emissions is related to the change in land and forest use, and for this reason, a high rate would not be necessary if emissions had to be reduced to the magnitude agreed by the country. If the tax rate was lower, the change in welfare would be positive.

Table 4 - Expected performance of Brazilian economy $\left(\tau_{e}=10 \%\right)$ - Long Term

\begin{tabular}{lccccc}
\hline \multicolumn{1}{c}{ Discrimination } & Current & Without DD & DD $\boldsymbol{\tau}_{\boldsymbol{C}}$ & DD $\boldsymbol{\tau}_{\boldsymbol{h}}$ & DD $\boldsymbol{\tau}_{\boldsymbol{K}}$ \\
\hline Tax collection * & & & & & \\
Consumption tax & $16.02 \%$ & $15.92 \%$ & $15.03 \%$ & $16.00 \%$ & $15.92 \%$ \\
Labor Income tax & $10.79 \%$ & $10.63 \%$ & $10.63 \%$ & $9.66 \%$ & $10.63 \%$ \\
Capital gains tax & $5.10 \%$ & $5.02 \%$ & $5.02 \%$ & $5.02 \%$ & $4.13 \%$ \\
Emissions tax & - & $1.23 \%$ & $1.23 \%$ & $1.23 \%$ & $1.23 \%$ \\
Total & $31.91 \%$ & $32.81 \%$ & $31.91 \%$ & $31.91 \%$ & $31.91 \%$ \\
Macroeconomic Variables ** & & & & & \\
Output & - & $-2.08 \%$ & $-1.36 \%$ & $-0.65 \%$ & $-0.12 \%$ \\
Consumption & - & $-2.65 \%$ & $-1.71 \%$ & $-0.78 \%$ & $-0.75 \%$ \\
Capital stock & - & $-3.54 \%$ & $-2.82 \%$ & $-2.12 \%$ & $0.44 \%$ \\
Hours worked & - & $-0.68 \%$ & $0.06 \%$ & $0.78 \%$ & $-0.64 \%$ \\
Environmental Variables $* *$ & & & & & \\
Environmental Quality & - & $6.33 \%$ & $6.25 \%$ & $6.18 \%$ & $6.12 \%$ \\
Emissions & - & $-38.22 \%$ & $-37.76 \%$ & $-37.32 \%$ & $-36.98 \%$ \\
Gain/loss * wellness * & - & $-0.05 \%$ & $0.14 \%$ & $0.33 \%$ & $0.59 \%$ \\
\hline Note: DD
\end{tabular}

Note: DD $=$ double dividend.

* Percentage of GDP

** Percentage variation compared to the steady state value.

The transition trajectories between the two stationary states are shown in Figure 5. It can be observed that when the double dividend thesis is applied to the consumption tax reduction, we have a less intense reduction in the short term in the levels of production, consumption and capital stock, when compared to the scenario without the introduction of double dividend thesis. However, we noticed that the trajectory of hours worked differs from that observed in the scenario without a double dividend, with a small fall in the short term and a recovery that causes hours worked in the long term larger than those in the initial steady state. These results are materialized in a more sustainable increase in welfare that reaches a value close to $0.2 \%$ in the short term.

Regarding the results of the scenario, where the reduced tax rate is on labor income, we observe that the fall in production and in the capital stock is even lower 
than in the previous case. In turn, it is in this scenario that the smallest reduction in consumption is observed in the short term, of which only after the 45 th period was it equal to the reduction observed in the capital gains tax rate scenario. In relation to hours worked, this scenario was able to generate a relatively strong increase in the percentage value in relation to the initial steady state, which was sustained until the final steady state. Social security increased more than in the scenario discussed above.

\section{Figure 5 - Transition trajectory of the simulation of Double Dividend Thesis}

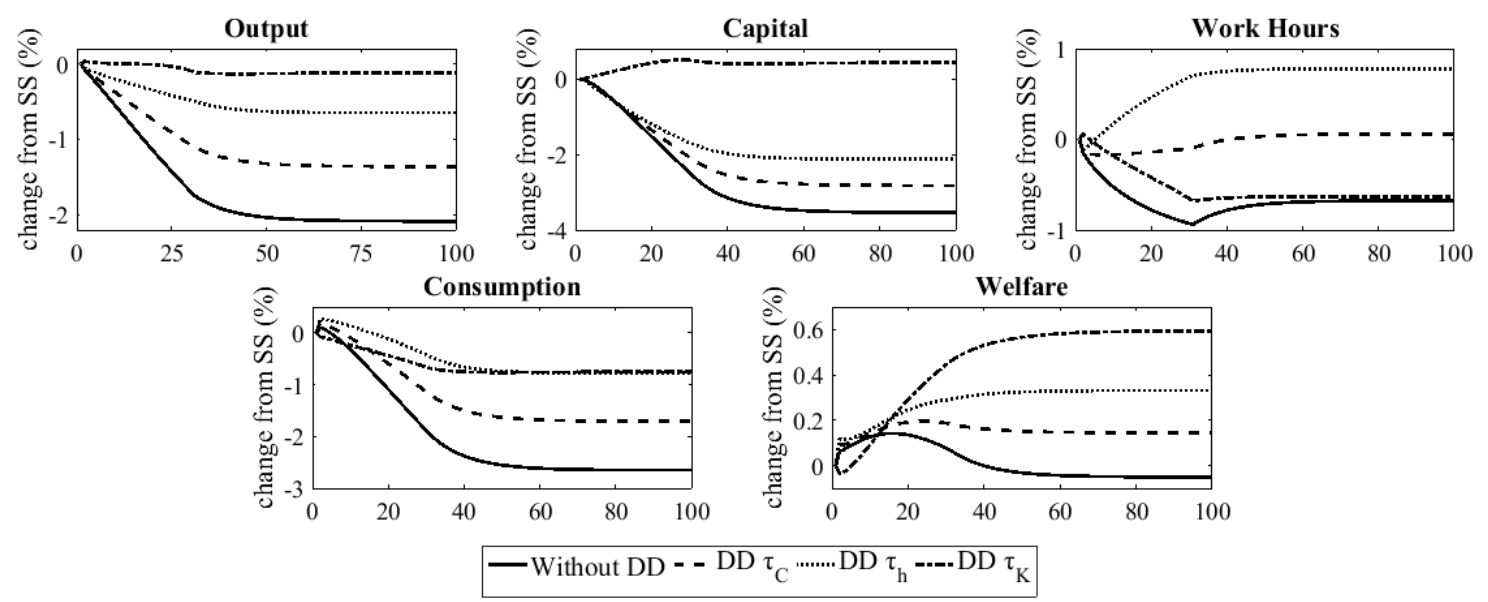

Finally, in which the capital income tax rate is reduced, as already mentioned, is what brings the greatest economic benefits. The fall in output in the short term is almost insignificant, while consumption falls more than in other scenarios in the very short term, but it recovers in the medium and long terms. The capital stock increases in the short term and has a very different trajectory than that presented by other scenarios. The hours worked have a trajectory very close to that presented in the scenario without the double dividend, but, however, has a more modest fall. In relation to welfare, it is perceived that there is a fall in the short term, which is not observed in the other cases, but whose direction is rapidly reversed, reaching a variation rate of medium and long-term, well above the other scenarios.

Figure 5 shows that the best economic results are achieved when the capital gains tax is chosen to be reduced. Regarding the environmental variables, the differences were very small, but the reduction of the consumption tax rate generated the best results $-6.25 \%$ improvement in the environmental quality and $37.76 \%$ reduction in emissions. 


\section{Conclusion}

This article sought to analyze the economic and environmental impacts of introducing of the Pigouvian tax on GHG emissions in Brazil, considering that the country signed the Paris agreement and submitted its climate action plan (INDC) to COP-21. The analysis was performed considering the target of reducing GHG emissions by $37 \%$ in a period of 30 years, starting in 2014, the base period for the calibration of the model. Initially, simulation exercises for different emission tax values were performed until the $37 \%$ reduction target was reached. The value found for the tax rate was approximately $10 \%$, which corresponds to US\$100.00 per ton of $\mathrm{CO}_{2}$, and would generate an annual collection of $1.23 \%$ of GDP.

The introduction of this tax would reduce output, consumption, capital stock and hours worked, but would improve the environmental quality enough to increase the welfare of the agents in the short term and maintain it practically in the long term.

We tested the double dividend hypothesis, reducing other taxes rates on the economy in the exact proportion of the increase in tax collection, keeping total government revenue stable. The results showed that the double dividend thesis was observed in case of Brazil, but only in the short term. In other words, in the initial periods, there was an increase in welfare resulting from the improvement in environmental quality together with an improvement in welfare resulting from the reduction of tax distortions in the economy. In the long term, we do not observe an increase in the level of welfare resulting from the improvement in environmental quality, for the parameterization adopted. The best economic results were observed when the capital income tax rate was reduced.

One of the limitations of the study lies in the fact that the model does not encompass the relationships between land and forest, which is where the largest GHG emissions in Brazil occur. As a result, we had to use a higher tax rate than was necessary for the country to reach the target set in the Paris agreement. Another possible limitation is the use of homogeneous agents, which makes it impossible to analyze distribution of inequalities when simulating the double dividend thesis

Therefore, despite the limitations mentioned, the evidence presented reinforces the thesis that the introduction of a Pigouvian tax on emissions is not only capable of achieving the internationally agreed targets, but also of generating 
a double improvement of environmental quality and reduction of distortions in the tax system, at least in the short term.

\section{References}

ANGELOPOULOS, K.; ECONOMIDES, G.; PHILIPPOPOULOS, A. What is the best environmental policy? Taxes, permits and rules under economic and environmental uncertainty. Working Paper $N^{\circ}$ 2980. CESifo, 2010.

ANNICCHIARICO, B.; DIO, F. D. GHG emissions control and monetary policy. Environmental and Resource Economics, v. 67, n. 4, p. 823-851, 2017.

ARAÚJO, C. H. V.; FERREIRA, P. C. G. Reforma tributária, efeitos alocativos e impactos de bem-estar. Revista Brasileira de Economia, v. 53, n. 2, p. 133-166, 1999.

BABIKER, M.; REILlY, J. M.; JACOBY, H. D. The Kyoto Protocol and developing countries. Energy Policy, v. 28, n. 8, p. 525-536, 2000.

BRAZIL. Intended Nationally Determined Contribution: towards achieving the objective of the United Nations framework convention on climate change. Available at: https://www4.unfccc.int/sites/ndcstaging/PublishedDocuments/Brazil\%20First/BRAZ IL\%20iNDC\%20english\%20FINAL.pdf.

FEIJÓ, F. T.; JÚNIOR, S. P. O protocolo de Quioto e o bem-estar econômico no Brasil: Uma análise utilizando equilíbrio geral computável. Análise Econômica, v. 27, n. 51, p. 127-154, 2009.

FERREIRA FILHO, J. B. de S.; ROCHA, M. T. Economic evaluation of public policies aiming the reduction of greenhouse gas emissions in Brazil. Journal of Economic Integration, v. 23, n. 3, p. 709-733, 2008.

FISCHER, C.; HEUTEL, G. Environmental macroeconomics: Environmental policy, business cycles, and directed technical change. Annual Review of Resource Economics, v. 5, n. 1, p. 197-210, 2013.

GURGEL, A. C.; PALTSEV, S. Costs of reducing GHG emissions in Brazil. Climate Policy, v. 14, n. 1, p. 209-223, 2014.

HEUTEL, G. How should environmental policy respond to business cycles? Optimal policy under persistent productivity shocks. Review of Economic Dynamics, v. 15, n. 2, p. 244-264, 2012. 
KOSSOY, A.; PESZKO, G. State and Trends of Carbon Pricing 2015. Washington: World Bank, 2015.

LANDRIGAN, P. J. Air pollution and health. The Lancet Public Health, v. 2, n. 1, e4-e5, 2017.

LEAL, R. A.; ELY, R. A.; UHR, J. G. Z.; UHR, D. de A. P. Ciclos Econômicos e Emissão de $\mathrm{CO}_{2}$ no Brasil: Uma Análise Dinâmica para Políticas Ambientais Ótimas. Revista Brasileira de Economia, v. 69, n. 1, p. 53-73, 2015.

LUCENA, A. F. P.; CLARKE, L..; SCHAEFFER, R.; SZKLO, A.; ROCHEDO, P. R. R.; NOGUEIRA, L. P. P.; DAENZER, K.; GURGEL, A.; KITOUS, A.; KOBER, T. Climate policy scenarios in Brazil: a multi-model comparison for energy. Energy Economics, v. 56, n. 1, p. 564-574, 2016.

NORDHAUS, W. D. A Question of Balance: Weighing the Options on Global Warming Policies. New Haven: Yale University Press, 2008.

PARTNERSHIP FOR MARKET READINESS. Carbon Tax Guide: A Handbook for Policy Makers. Washington: World Bank, 2017. Available at: https://openknowledge.worldbank.org/handle/10986/26300.

PEREIRA, A. M.; PEREIRA, R. M. What is it going to take to achieve 2020 Emission Targets? Marginal abatement cost curves and the budgetary impact of $\mathrm{CO}_{2}$ taxation in Portugal. Working Papers 105, Department of Economics, College of William and Mary, 2014.

SECRETARIA DA RECEITA FEDERAL DO BRASIL. Carga Tributária no Brasil - 2015 (Análise por Tributo e Bases de Incidência). Brasília: RFB, 2016.

SYSTEM STUDY GREENHOUSE GAS EMISSIONS ESTIMATES - SEEG. Carbon Emission in Brazil. Available at http://seeg.eco.br/.

VIGUIER, L. L.; BABIKER, M. H.; REILLY, J. M. The costs of the Kyoto Protocol in the European Union. Energy Policy, v. 31, n. 5, p. 393-483, 2003. 


\section{Appendix}

Figure A.1 - Transition trajectory of the simulation of different values for emission tax for 2010, 2012 and 2014
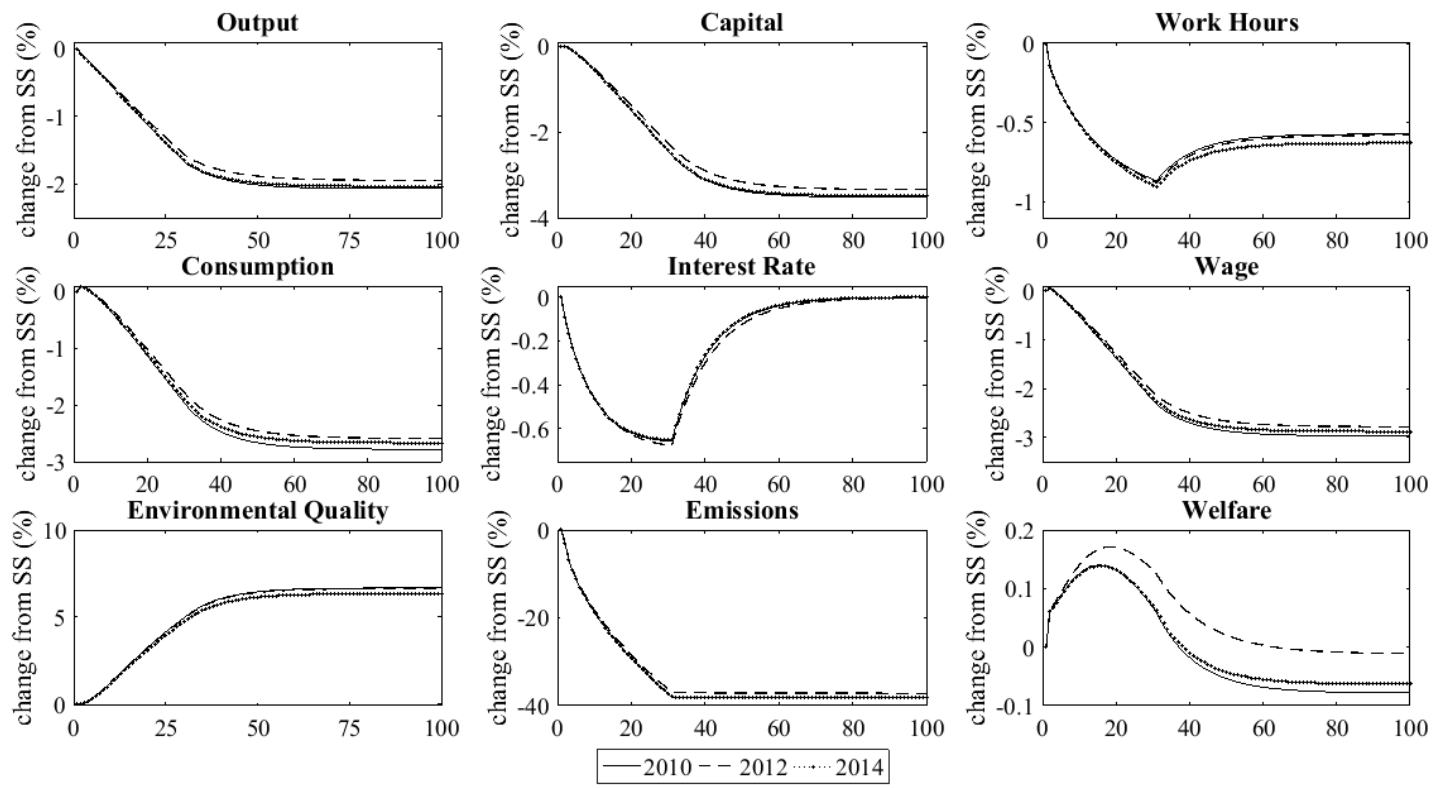

Note: Values reported in the caption for $\tau_{e}$ are only assumed after the 30th period. Between the first period, which assumes a value equal to $0.1 \%$, and at period 30 , the rate increases linearly. 